\title{
Investigating ERP Misalignment between ERP Systems and Implementing Organizations in Developing Countries
}

\author{
Nkosinathi Bitsini
}

\author{
University of Cape Town, Department of Information Systems, South Africa
}

Received date: 9 September 2015; Accepted date: 7 January 2015; Published date: 02 April 2015

Academic Editor: Mohamad Rosli

Correspondence should be addressed to: Nkosinathi Bitsini; Nko.bitsini@gmail.com

Copyright (C) 2015 Nkosinathi Bitsini. Distributed under Creative Commons CC-BY 4.0

\begin{abstract}
The adoption of enterprise resource planning (ERP) systems by organizations from developing countries has increased dramatically. The continued growth of ERP adoption in developing countries is accompanied by high failure rates which makes it impossible for these organizations to enjoy the full realization of benefits. Many ERP systems' failures are associated with the misalignment between the ERP requirements and the expectations of the client. 70 percent of ERP implementations fail to deliver the anticipated benefits with estimates that developing countries make up some 10 to 15 percent of global ERP sales (Hawari \& Heeks, 2010). ERP systems do not usually fit the requirements of the implementing organizations in developing countries because of the different business practices, and legal and government regulations. There is a sizeable gap between the assumptions and requirements built into the designs of ERP systems and the realities of the client. Until academics, organizations, vendors and consultants understand better the phenomenon of misfit, the realization of benefits from ERP systems is likely to remain difficult and unpredictable on practical perspective. This paper seeks to investigate the complexities inherent in the ERP systems, which subsequently result in misalignment and this will equip decision makers to better prepare strategies that will increase the probability of realizing the desired results. This paper will contribute directly or indirectly to the reduction of failure rate of ERP projects on developing countries associated with misfit.
\end{abstract}

Keywords: Enterprise Resource Planning (ERP), ERP failure, misalignment, developing country.

\section{Introduction}

The continued high failure rates with enterprice resource planning (ERP) systems remain a great concern (Ram, Corkindale \& $\mathrm{Wu}$, 2013). 70 percent of ERP implementations fail to deliver the anticipated benefits with estimates that developing countries make up some 10 to 15 percent of global ERP sales (Hawari \& Heeks,
2010). Many ERP systems' failures in developing countries are associated with the misalignment of requirements between ERP systems and implementing organizations (Roseann \& Weber, 2004); Morton \& $\mathrm{Hu}$, 2008; Strong and Volkoff, 2010).

ERP systems do not usually fit the requirements of organizations in developing countries because of the different business 
practices, and legal and government regulations. There is a sizeable gap between the assumptions and requirements built into the designs of ERP systems and the realities of the client. Deodar and Aiming (2011) argue that when organizations implement an ERP system that was developed in a different social context, they are more likely to experience misalignment or misfit. Embedded within software packages are business models that their designers believe represent the best practice in certain contexts (Roseann et al, 2004). This is because software packages are subjected to institutional procedures, processes and forces that set rules of rationality (Gosain, 2004).

These institutional forces are an important embodiment of institutional commitments and serve to bind organizations to fundamental choices about how organizational activities should be organized (Sia and Soh, 2007). The purpose of this paper is to unpack and highlight the complexities inherent in western developed ERP systems, subsequently creating an understanding of the consequences associated with the use of such systems in a different contextual environment. The understanding of ERP misalignment will induce and help implementing organizations to improve their ability to implement and configure ERP systems successfully.

The understanding of this phenomenon will equip decision makers (management) to prepare strategies that would increase the probability of benefits realization. There is a need for an explicit understanding of the reasons for the misfit; understanding it encompasses two simultaneous complexities namely multiple organizational elements and technical elements (Strong and Volkoff, 2010). Organizational elements include issues like project management, change management, organizational culture, management buy-in, user participation, communication, training and other related factors. Technical elements include issues like IT infrastructure such as computers, telecommunications, internet, mobile telecommunication, and servers, technical skills and experts required. A careful assessment of the factors contributing to the misalignment with ERP implementation would be of benefit to both implementing organizations and ERP software vendors.

The rest of this paper is structured as follows: the first section explains the phenomenon of ERP misalignment using theoretical lenses; the second explores the ERP misalignment categories; the third section gives an account of the current state of ERP adoption in developing countries and subsequently the challenges confronted by developing countries; the firth section explains the adoption of ERP in the public sector; and lastly the benefits associated with ERP systems are given.

\section{Theories Context}

Looking at ERP implementation through the lens of institutional and structuration theory provides fresh insights that may help organizations better understand and manage ERP systems to achieve success. DeSanctis \& Poole (1994) believe that software packages, as IT artifacts, embody structuration properties. The type of research that treats both technology and the organization as objects is assuming technology is an object capable of having an impact on social systems. Giddens proposed what he calls the duality of structure, which refers to the structure or institutional properties of social systems as being created by human actions and serve to shape future human actions (Giddens, 1976). In Giddens' theory, structure is being assumed and understood to be an abstract of a social sysem.

Giddens stipulates that all human interaction is inextricably composed of structures of meaning, power, and moral framework and that all interactions can be analysed in terms of them. Orlikowski \& Robey (1991) recommend that any explanation of social phenomena must thus refer to both the role of human action and the effects of existing institutional properties. They further specify three modalities that link the realm of action and the realm of social structure as interpretive schemes, resources and norms. Interpretive schemes are shared, standardized stocks of knowledge that individuals draw on to interpret behavior and events. 
Resources are the means by which intentions are realized, goals are accomplished and power is exercised. Norms are the rules governing sanctioned or appropriate conduct, and they are the legitimacy of interaction within a setting's moral order. According to Gosain (2004), software packages are subjected to institutional procedures, processes and forces that set rules of rationality.

These institutional forces are an important embodiment of institutional commitment and serve to bind organizations to fundamental choices about how organizational activities should be organized (Sia \& Soh, 2007). Technology creators, together with the developers of software packages, inscribe their views of the world in the technology they build (Latour, 1992) and, as such, the designer's view of the world is subject to their own institutional context (Soh and Sia, 2004).

Sia \& Soh (2007) argue that the institutional context that software package developers attempt to represent is heavely influenced by their selected referent organizations and these referent organizations tend to be from the developers' own country. Most ERP systems are developed by North America or North Europe and these Software packages developed on one set of institutional context may not fit organizations operating in a different institutional context hence misfit or misalignment is likely to occur. Institutional theory acknowledges the fact that institutional context can differ. These institutional forces and models comes from different spheres and categories, the following section explains misfit or misalignment categories that emerged from the literature.

\section{Misalignment or Misfit Categories}

ERP systems are generally designed and programmed by independent organizations outside the client companies (Francoise et al, 2009). Hawari \& Heeks (2010) conducted a study from a developing country's perspective and they discovered that there is a design-reality gap. The assumptions made when developing ERP systems do not address the reality or requirements expected by the implementing organizations, especially organizations from developing countries.

\section{Information}

Data or information misfits occur when data or data characteristics stored in or needed by the ERP system lead to data quality issues such as inaccuracy, inconsistent representations, inaccessibility, and lack of timeliness or inappropriateness for the users' contexts (Strong \& Volkoff, 2010). In a case study conducted by Hawari \& Heeks (2010), the designer of the software package assumed the existence of data that was not in fact readily available such as a list of accurate quantities of all items or materials stored in the company's warehouse, a list of all the company's suppliers and core data related to the creation of a bill of materials for the products. Some of the data required by the ERP system design simply did not exist in the company.

\section{Technology}

In the case study conducted by Hawari \& Heeks (2010), the designer of the software package assumed the existence of a strong local area network, servers, personal computers and broadband internet connections. Developing countries are not on an equal footing with developed countries when it comes to technology. Kaunda and Kennedy (2013) argue that developing countries are still far less than developed countries in many areas of technological environment and infrastructure perhaps because the technology is manufactured in developed countries.

\section{Role and Skills}

A role misfit occurs when the roles in the ERP system are inconsistent with the skills available, creating imbalances in the workload leading to bottlenecks and idle time, or generate mismatches between responsibility and authority (Strong \& Volkoff, 2010). Hawaii and Heels discovered that assumptions built into the software required role changes that created organizational problems. Leavitt and Whistler (1958) predicted that information technology is likely to have a significant effect on the future nature of managerial 
jobs and the future shape of the organization.

ERP design requires the existence of a modern management structure that allows decentralized decision making by giving operational-level employees both access to information, and empowering them to make decisions (Rajapakse and Seddon, 2005b). However in Hawaii and Heels' case study, it was a different case. The firm had a centralized management structure with centralized data access and centralized decision making which still resulted in ERP failure as some managerial positions were vacant and changes needed to be made to supervisory responsibilities.

Hawari \& Heeks (2010) discovered that ERP developers assume the full-time assignment of client staff members who engage with the implementation process to explain current organizational processes and to help introduce best practice. They found that, in reality, some of the competencies and skills that were assumed were not present in the implementing organization. There is a need for a clear understanding of enablers that can assist on ERP implementation in capacitating IS practitioners and these are explained in the following section

\section{Processes}

According to Yen \& Sheu (2004), almost every organization would discover some inconsistencies between the ERP system and its current processes and organizational structure; because ERP system design assumes a set of organizational processes that match the best practice in the industry (Strong \& Volkoff, 2010). Successful implementation of an ERP system generally requires an organization to adopt the standardized business processes embedded in the software and to move away from a function based organizational structure in favour of an integrated and process-oriented structure (Morton \& Hu, 2008).

The internal structure of an ERP system is not necessarily aligned with the implementing organization's existing structure. Standard practice in many ERP implementations has been to force a match between client business processes and ERP system design through business process re- engineering (BPR) which results in too much change and ultimately leads to failure (Hawari \& Heeks, 2010).

\section{Organizational Culture}

ERP systems were mainly initiated by large organizations in the West (Rajapakse \& Seddon, 2005). Because of different cultural and business practices in developing countries, these problems of fit may be more pronounced in developing countries (Heeks, 2002). Business practices embedded in western-based ERP systems are likely to reflect European organizational or national cultures (Martinsons, 2004) so, when such systems are implemented in Africa, problems may be experienced due to the misalignment between cultural assumptions and practices embedded in the software and those of the client organization. Some of the controls embedded in the software packages provide too much control, inhibiting productivity, or too little control, leading to the inability to assess or monitor performance appropriately (Strong \& Volkoff, 2010).

\section{Other Resources}

ERP implementation and design requires two types of expenditure; one-time cost to rollout the system and costs (Hawari \& Heeks, 2010). Given the fact that developing countries suffer from limited resources like shortage of computers, telecommunications, internet, mobile telecommunication and servers constitutes the basic prerequisite for ERP implementation and these resources are accompanied by money. Hawaii and Heels (2010) conducted a study from a developing country they came to conclusions that money is a major issue for developing countries for ERP implementation. The following section demonstrates the current context of ERP adoption in developing countries.

\section{ERP Adoption in Developing Countries}

Developing countries have become a major target for ERP vendors (Dezdar and Ainin, 2011). However, the issue of misalignment or misfit has been infrequently or poorly studied in relation to developing countries. Developing countries' expenditure on ERP is growing and these systems can indisputably 
deliver benefits to organizations in developing countries (Hawari and Heeks, 2010). Many organizations from developing countries have implemented ERP systems in the past few years and the ERP market continues to grow at a compounded annual growth rate of 11\% (Damijan, Andrej and Mojca, 2009).

However, the continued growth of ERP implementation in developing countries is accompanied by a high rate of failure that is associated with a number of factors such as lack of skills and technology, absence of good quality data, lack of money, user resistance and cultural issues (Kamhawi, 2008; Soja, 2009; Hawari \& Heeks, 2010). ERP vendors continue to target developing countries for the purpose of identifying new sales growth locations (Hawari \& Heeks, 2010).

But developing nations are still lagging behind in ICT adoption because they suffer from human, social, economic and political challenges (Kamal and Qureshi, 2009; Kyobe, 2011). South Africa in particular faces several challenges and these include limited skills in ICT, low levels of ICT research and development investment, lack of a critical mass of high-quality research to enhance innovation, high telecommunications' costs and lack of proper economic models for providing connectivity to the marginalized rural communities (Kyobe, 2011).

\section{ERP Challenges in Developing Countries}

\section{Infrastructure}

Developing countries are regarded and considered to be relatively poor and rank low in aggregate indicators such as personal income, life expectancy and literacy (World Bank, 2012) and as such IT infrastructure like computers, telecommunications, internet, mobile telecommunication and servers constitutes the basic prerequisite for ERP implementation. Developing countries have been reported suffering from poor infrastructure by many researchers (Huang and Palvia, 2001; Kyobe, 2011).

Poor IT infrastructure in developing countries obviates the successful deployment of software packages (Maiye,
2012). According to Kyobe (2011), effective ICT adoption in developing countries is dependent on basic infrastructural requirements such as the availability and reliable supply of electricity, commitment of government and other stakeholders and affordable bandwidth.

\section{Economic factors}

The economic status of a country is a broad indicator of its IT and IS development. A sound economy provides a solid foundation for IT and IS development as well as ERP implementation (Huang and Palvia, 2001). Economic growth and development fuels IT and IS development and deployment. Kyobe (2011) maintains economics plays a key role in the adaptation of new technology.

Organizations in developing countries lack sufficient financial resources to acquire new and up-to-date technologies and may not properly evaluate returns on IT investments due to a lack of technical skills. Pavon and Brown (2010) also maintain that the economic development in a region impacts on accessibility and exposure to technologies, which in turn influences their adoption and diffusion.

\section{Implementation Cost}

For every organization, cost has remained one of the most crucial aspects of ERP implementation irrespective of the size or sector (Seymour, 2014). Feng, Hu \& Huang (2011) argue that ERP implementations are the most difficult projects to undertake because of their complexity, high cost and adaptation risks. In the majority of ERP projects, direct or indirect costs rise above anticipated figures. The price of proprietary software is economical when compared to in-house development and the total cost of in-house implementation might even be three to five times more compared to the application purchase price. The literature on ERP divides ERP implementation costs into direct and indirect costs.

Direct costs include IT infrastructure, hardware costs (severs, clients, storage and networking) and software costs (operating system ERP license, data management system). Other direct costs include initial costs of the system, customization costs, cost 
of migrating data from the old system to the new system, cost of integrating modules, annual maintenance costs and vendor project management (Seymour, 2014). Indirect costs include cost of training, reorganisation costs, consultation fees, ongoing support and hidden implementation costs, costs of hiring, project management and business management (Seymour, 2014).

According to 2014 Panorama report, 54\% of ERP projects were reported to have exceeded their allocated budget. When the respondents were asked further questions as to why the projects went over budget, $17 \%$ of the respondents indicated that the project scope was expanded and 15\% noted that unexpected technical and organizational issues created additional costs. ERP implementation is perceived to be very expensive which blocks or delays the deployment of the software packages.

\section{Political Factors and State Policies}

ICT adoption raises a number of political questions, and politics and government policy may also have serious implications for the adoption process (Corrales and Westhoff, 2006). Corrales and Westhoff (2006) studied the impact of political persuasions on IT adoption and they claim that ICT adoption is associated with issues of political liberties in many ways, i.e. knowledge based technologies may foster liberties, democratization, human rights and social empowerment. However, the government often operates national communications directly, largely because the private sector is often incapable of operating such infrastructure.

GDP, per capita income and human/physical capital are considered to play a major role in technology adoption. Corrales and Westhoff (2006) argue that the levels of technology adoption respond to specific state policies. Government policies about tax and tariff subsidies, rules and regulations, restrictions, incentives and support for a particular technology, social programmes that favour technical education in schools, all play an important role in its acceptance or rejection. There is a need for the government to implement relevant policies that can address the shortage of IT skills and human capital in developing countries.

\section{Other Challenges}

Nowadays, ERP systems are increasingly adopted by organizations of every kind and size, in order to avoid technical obsolescence and to create sustainable competitive advantages (Maditinos, Chatzoudes, \& Tsairidis, 2011), yet there is appreciable evidence of increasing global implementation failures in ERP projects. As highlighted above, many ERP projects have been reported to be over budget and to have overrun the implementation schedule.

According to the recent research, challenges threatening ERP implementation are not technologically related issues like technological complexity, compatability or standardization but mostly organizational and human related issues like resistance to change, organizational culture, incompatible business processes, poor project management, lack of top management support and so on. ERP implementations have sometimes failed to achieve the organization's targets and desired outcomes leading to a complete failure. Failures can be explained by the fact that ERP implementation forced companies to follow the principle of best practices using as a model the most successful organizations and from appropriate reference models.

\section{ERP in the Public Sector}

Implementation of ERP systems in the public sector has long been acknowledged as being problematic with enormous investment and risk of failure (Kelemen, 2014), yet the public sector has remained an attractive customer mainly due to its great size (Ontario, 2005). Chang, Gable, Smythe \& Timbrell (2000) argue that the continued increase of ERP adoption by the public sector leads to the replacement of existing operating systems. The public sector is still growing and the particularities of the public sector make specific studies necessary (Alves \& Matos, 2011).

In response to the growing demand from the public sector, major ERP vendors have developed specific public sector functionality and have started planning public sector oriented enhancements to their systems (Kelemen, 2014). The continued increase in ERP adoption by the 
public sector is associated with various benefits such as integrated real time information, better administration and results based management. However, the increasing adoption of ERP by public sector enterprises has significantly lagged the private sector. According to Beal \& Prabhakar (2010), software vendors and system integrators have failed to adapt to the unique business requirements of the public sector.

When comparing ERP implementation between the public and private sector, culture has been identified as a major difference (Thomas and Jajodia, 2004). Because the private and public sectors operate in different contextual environments, public sector IT planning is oblidged to bow to political pressure and is thus mostly focused on the short term (Uwizeyemungu and Raymond, 2007; Alves \& Matos, 2011).

ERP public sector implementation also suffers from barriers such as political subdivision, public scrutiny and statutory constraints (Beal \& Prabhakar, 2010). Regardless of these shortcomings, ERP systems continue to provide the information backbone to governmental companies including the government to cope with the complexities of modern business and the global nature of today's markets (Powell, 2013). ERP vendors are now trying to further extend their market to major companies in developing countries including the public sector (Dezdar, 2012).

In 2006, the ARC Advisory Group stated that the ERP market is worth about $\$ 16.67$ billion and anticipated that it was going to be $\$ 21$ billion by the year 2010. Alves \& Matos (2011) argue that ERP systems were primarly targeted at manufacturing companies but now public organizations have invested considerable resources in the implementation of these systems. ERP systems have transformed private sector organizations and now are gaining acceptance in the public sector (Kelemen, 2014). Even though ERP adoption in the public sector increases rapiddly, developing countries are far less than developed countries in many areas, probably because of technolgical environment and infrastructure. Recardless of the high rate of failure on ERP implementation, the following benefits are associated with ERP systems.

\section{Potential Benefits}

Many studies have been conducted on ERP benefits (Esteves and Pastor, 2001; Esteves and Borhorquez, 2007), yet low awareness of the benefits of an end-to-end system has been acknowledged as the biggest problem (Esteves, 2009). Many organizations have not fully realized the potential benefits from ERP systems (Feng, Hu \& Huang, 2011). Regardless of the size, sector or scale of business, the awareness of the benefits of an enterprise solution is very critical. Many research findings continue to recognize the fact that organizations do not always realize the benefits they wish to achieve when pursuing ERP implementation (Schubert \& Williams, 2011).

The clear identification of the benefits associated with ERP systems is very crucial as this can help organizations to compare risks and costs versus the potential benefits (Feng, Hu \& Huang, 2011) ERP systems' benefits accrue at different stages, including but not limited to implementation and post implementation. According to Annamalai and Ramayah (2011), industries of all sizes are using ERP systems in order to improve their efficiency, profitability and business performance or to replace legacy systems to achieve a competitive advantage. The identification of the benefits set out in Table I below did not consider the question of at what stage is a benefit likely to occur. 
Table I: Critical Success Factors

\begin{tabular}{|c|c|c|}
\hline & Benefit & Reference \\
\hline \multirow{9}{*}{ Operational } & Cost reduction & \multirow{9}{*}{$\begin{array}{l}\text { Esteves and Pastor (2001); } \\
\text { Esteves and Borhorquez (2007); } \\
\text { Staehr (2007); } \\
\text { Saatcıolu (2009); } \\
\text { Schubert \& Williams (2011); } \\
\text { Annamalai \& Ramayah (2011); } \\
\text { Feng, Hu \& Huang (2011), } \\
\text { Norton, M. Thomas, J. Thomas \& } \\
\text { Ashurst (2012) }\end{array}$} \\
\hline & Cycle time reduction & \\
\hline & Productivity improvement & \\
\hline & Decreased financial closure cycle & \\
\hline & Lowered inventory levels & \\
\hline & Quicker information response time & \\
\hline & Improved order management/order cycle & \\
\hline & Improved on-time delivery & \\
\hline & More efficient business processes & \\
\hline \multirow{9}{*}{ Managerial } & Quality improvement & \multirow{9}{*}{$\begin{array}{l}\text { Esteves and Pastor (2001); } \\
\text { Esteves and Borhorquez (2007); } \\
\text { Staehr (2007); } \\
\text { Saatcioglu (2009); } \\
\text { Schubert \& Williams (2011); } \\
\text { Annamalai \& Ramayah (2011); } \\
\text { Feng, Hu \& Huang (2011) } \\
\text { Norton, M. Thomas, J. Thomas \& } \\
\text { Ashurst (2012) }\end{array}$} \\
\hline & Performance improvement & \\
\hline & Better resource management & \\
\hline & Improved decision making & \\
\hline & Improved cash management & \\
\hline & Better management and controlling functions & \\
\hline & Better control of flow of goods & \\
\hline & Improved information flow control & \\
\hline & Improved financial flow control & \\
\hline \multirow{5}{*}{ Strategic } & Supports business growth & \multirow{5}{*}{$\begin{array}{l}\text { Esteves and Pastor (2001); } \\
\text { Staehr (2007); } \\
\text { Saatcıoglu (2009); } \\
\text { Feng, Hu \& Huang (2011) }\end{array}$} \\
\hline & Generates product differentiation & \\
\hline & Improves interaction with customers & \\
\hline & Improves interaction with suppliers & \\
\hline & Increases revenue & \\
\hline Technical & Increased IT infrastructure capability & Feng, Hu \& Huang (2011) \\
\hline
\end{tabular}

\section{Conclusion}

The literature presented here highlights issues that invite further consideration with respect to ERP adoption, implementation and post implementation operation. The insight gained from the literature must be understood in the light of a number of restrictions. There are limited numbers of studies on ERP misalignment that have been undertaken in developing countries, particularly in South Africa. This demonstrates an urgent need for the better understanding of ERP implementation, adoption and utilization in developing countries, since these countries are experiencing a rapid increase in ERP implementation while they are still confronted by challenges related to infrastructure, politics, economics and cultural issues. From the literature outlined above, it is self-evident that ERP systems are introducing vendor culture and institutional properties into implementing organizations 
and these have significant implications to the implementing organizations. Implementing organizations are sometimes obliged to abandon their way of doing business which subsequently results in failure in providing goods and services to customers. Conflicts arise because there is no single universal business practice that can be assumed by the vendors which will fit all the different regions, countries, organizations and industries. In light of the gap identified from the literature in relation to business practice, this research seeks to fill the gap by studying ERP misalignment during implementation in the local context (South Africa) focusing on the public sector. The decision to focus on the public sector is informed by the fact that the public sector is characterized by a high rate failure for ERP projects according to the literature.

\section{Acknowledgements}

The author would like to thank several people. I would like to thank my supervisor Prof. Lisa Seymour and Prof. Michael Kyobe for the support and kindness they have shown me. Furthermore I would also like to express my special appreciation and thanks to Dr. Peter Inman for his assistance and guidance. I would also like to express my warm thanks to Mr. Fezile Ndema and Ms. Zola Ngoma for believing in me and their tireless support, love and kindness. Words cannot express how grateful I am to my CEO (Mr. Pepi Silinga) for all of the sacrifices that you have made on my behalf. I would also like to thank my family, friends and colleagues for their support.

\section{Reference}

1.Alter, S. (2006). "The Work System Method: Connecting People, Processes, and IT for Business Results,"Work System Method.

2.Alves, M. C. G. \& Matos, S. L. A. (2011). “An Investigation into the Use of ERP Systems in the Public Sector," Journal of the Enterprise Resource Planning Studies Volume Article ID, 950191

3.Annamalai, C. \& Ramayah, T. (2011). "Enterprise Resource Planning (ERP) Benefits Survey of Indian Manufacturing Firms: An Empirical Analysis of SAP Versus
4.Oracle Package," Business Process Management Journal, 17(3), 495-509.

5.Asemi, A. \& Jazi, M. D. (2010). “A Comparative Study of Critical Success Factors (Csfs) in Implementation of ERP in Developed and Developing Countries,".International Journal of Advancement in Computing Technology, 2(5), 99-110.

6.Bandura, A. (1989). "Human Agency in Social Cognitive Theory," American Psychologist, 44(9), 1175.

7.Beal, J. \& Prabhakar, B. (2010). "Public Sector ERP,"

8.Chang, A., Scheer, M., Grote, A., Schomburg, I. \& Schomburg, D. (2009). "BRENDA, AMENDA and FRENDA the Enzyme Information System: New Content and Tools in 2009," Nucleic Acids Research, 37(Database issue), D588-92. doi:10.1093/nar/gkn820 [doi]

9.Chang, S. I., Gable, G., Smythe, E. \& Timbrell, G. (2000). "A Delphi Examination of Public Sector ERP Implementation Issues," Proceedings of the Twenty First International Conference on Information Systems, 494-500.

10.Corrales, J. \& Westhoff, F. (2006). "Information Technology Adoption and Political Regimes," International Studies Quarterly, 50(4), 911-933.

11.Damijan, Z., Andrej, K. \& Štemberger, M. I. (2009). "The Influence of Business Process Management and Some Other Csfs on Successful ERP Implementation," Business Process Management Journal, 15 (4) 588 608.

12.Davison, R., Martinsons, M. G. \& Kock, N. (2004). "Principles of Canonical Action Research," Information Systems Journal, 14(1), 65-86.

13.DeSanctis, G. \& Poole, M. S. (1994). "Capturing the Complexity in Advanced Technology Use: Adaptive Structuration Theory," Organization Science, 5(2), 121147. 
14.Dezdar, S. (2012). "Strategic and Tactical Factors for Successful ERP Projects: Insights from an Asian Country," Management Research Review, 35(11), 1070-1087.

15.Dezdar, S. \& Ainin, S. (2011). "The Influence of Organizational Factors on Successful ERP Implementation," Management

Decision, 49(6), 911-926.

16.Esteves, J. (2009). “A Benefits Realisation Road-Map Framework for ERP Usage in Small and Medium-Sized Enterprises," Journal of Enterprise Information Management, 22(1/2), 25-35.

17.Esteves, J. \& Bohorquez, V. (2007). “An Updated ERP Systems Annotated Bibliography: 2001-2005," Instituto de Empresa Business School Working Paper No. WP 07-04 , 19(1), 18.

18.Françoise, O., Bourgault, M. \& Pellerin, R. (2009). "ERP Implementation through Critical Success Factors' Management," Business Process Management Journal, 1 (3), 371-394.

19.Gidden, A. (1976). 'New rules of Sociological Method,' Basic Books. New York.

20.Gosain, S. (2004). "Enterprise Information Systems as Objects and Carriers of Institutional Forces: The New Iron Cage?," Journal of the Association for Information Systems, 5(4), 6.

21.Hawari, A. \& Heeks, R. (2010). "Explaining ERP Failure in A Developing Country: A Jordanian Case Study," Journal of Enterprise Information Management, 23(2), 135-160.

22.Hawking, P. (2007). "Implementing ERP Systems Globally: Challenges and Lessons Learned for Asian Countries," Journal of Business Systems, Governance and Ethics, 2(1), 21-32.

23.Heeks, R. (2002). "Information Systems and Developing Countries: Failure, Success, and Local Improvisations," The Information Society, 18(2), 101-112.
23.Hossain, M. M. \& Jahed, M. A. (2010). 'Factors Influencing on the Adjustment of ERP System during Implementation,' Global Management Review, 4(3).

24.Huang, Z. \& Palvia, P. (2001). "ERP Implementation Issues in Advanced and Developing Countries," Business Process Management Journal, 7(3), 276-284.

25.Kamal, M. \& Qureshi, S. (2009). "An Approach to IT Adoption in MicroEnterprises: Insights into Development," MWAIS 2009 Proceedings, 36.

26.Kamhawi, E. M. (2008). "Enterprise Resource-Planning Systems Adoption in Bahrain: Motives, Benefits, and Barriers," Journal of Enterprise Information Management, 21(3), 310-334.

27.Kaunda, M., J. \& Kennedy, O. (2013). 'Factors Influencing Adoption and Use of Information and Communication Technology at the Ethics and Anticorruption Commission of Kenya,' Journal of Business Administration and Management Sciences Research, 2(11), 224-309.

28.Kelemen, R. (2014). "ERP Systems in Public Sector," Information and Communication Technology, Electronics and Microelectronics (MIPRO), 2014 37th International Convention on, 1537-1543.

29.Kyobe, M. (2011). "Investigating the Key Factors Influencing ICT Adoption in South Africa," Journal of Systems and Information Technology, 13(3), 255-267.

30.Latour, B. (1992). "Ciencia en Acción,".

31.Leavitt, H. J. \& Whisler, T. L. (1958). Management in the 1980's November.

32.Liu, L., Feng, Y., Hu, Q. \& Huang, X. (2011). "From Transactional User to VIP: How Organizational and Cognitive Factors Affect ERP Assimilation at Individual Level," European Journal of Information Systems, 20(2), 186-200.

33.Martinsons, M. G. (2004). "ERP in China: One Package, Two Profiles," Communications of the ACM, 47(7), 65-68. 
34.Maditinos, D., Chatzoudes, D. \& Tsairidis, C. (2011). "Factors Affecting ERP System Implementation Effectiveness," Journal of Enterprise Information Management, 25(1), 60-78.

35.Miranda, R. (1999). "The Rise of ERP Technology in the Public Sector," Government Finance Review, 15, 918.

36.Mkwazi, G. \& M Lisa, S. (2014). 'The Growth Trend of Small to Medium Size Enterprises Adopting Enterprise Resource Planning Systems: An Analysis of Business Cases in Zimbabwe and South Africa,' 1st Conference On Emerging Trends For Suitable Development And Human Capacity Building In The Third World Nations. The institute of African studies, University of Ghana.

37.Morton, N. A. \& $\mathrm{Hu}, \quad$ Q. (2008). "Implications of the Fit Between Organizational Structure and ERP: A Structural Contingency Theory Perspective," International Journal of Information Management, 28(5), 391-402.

38.Mukwasi, C. M. \& Seymour, L. F. (2014). "The Growing Trend of Small to MediumSized Enterprises Adopting Enterprise Resource Planning Systems: An Analysis of Business Cases in Zimbabwe and South Africa," Journal of Emerging Trends in Economics and Management Sciences, 5(7), 138-145.

39.Norton, A. L., Coulson-Thomas, Y. M., Coulson-Thomas, C. J. \& Ashurst, C. (2012). "Delivering Training for Highly Demanding Information Systems," European Journal of Training and Development, 36(6), 646-662.

40.Orlikowski, W. J. \& Robey, D. (1991). "Information Technology and the Structuring of Organizations," Information Systems Research, 2(2), 143-169.

41.Pavon, F. \& Brown, I. (2010). "Factors Influencing the Adoption of the World Wide Web For Job-Seeking in South Africa: Original Research," South African Journal of Information Management, 12(1), 1-9.
42.Peslak, A. R. (2006). "Enterprise Resource Planning Success: An Exploratory Study of the Financial Executive Perspective," Industrial Management \& Data Systems, 106(9), 1288-1303.

43.Powell, D., Riezebos, J. \& Strandhagen, J. 0. (2013). "Lean Production and ERP Systems in Small-And Medium-Sized Enterprises: ERP Support for Pull Production," International Journal of Production Research, 51(2), 395-409.

44.Prakash, N. \& Rolland, C. (2006). "System Design for Requirements Expressed as a Map," Proceedings of Information Resources Management Association,

45.Rajapakse, J. \& Seddon, P. B. (2005). “ERP Adoption in Developing Countries in Asia: A Cultural Misfit," 28th Information Systems Seminar in Scandinavia, Kristiansand, 6-9.

46.Ram, J., Corkindale, D. \& Wu, M. (2013). "Implementation Critical Success Factors (Csfs) For ERP: Do They Contribute To Implementation Success And PostImplementation Performance?," International Journal of Production Economics, 144(1), 157-174.

47.Raymond, L. \& Uwizeyemungu, S. (2007). "A Profile of ERP Adoption in Manufacturing SMEs," Journal of Enterprise Information Management, 20(4), 487-502.

48.Rosemann, M., Vessey, I. \& Weber, R. (2004). "Alignment in Enterprise Systems Implementations: The Role of Ontological Distance," International Conference on Information Systems (ICIS) 2004 Proceedings.

49.Saatçioglu, Ö. Y. (2009). "What Determines User Satisfaction in ERP Projects: Benefits, Barriers or Risks?," Journal of Enterprise Information Management, 22(6), 690-708.

50.Scheckenbach, T., Zhao, F., Allard, E., Burke, J., Chiwaki, K. \& Marlow, S. (2014). "Issues of ERP Upgrade in Public Sectors: A Case Study," Human-computer interaction. applications and services (pp. 754-763) Springer. 
51.Schubert, P. \& Williams, S. P. (2011). "A Framework for Identifying and Understanding Enterprise Systems Benefits," Business Process Management Journal, 17(5), 808-828.

52.Sia, S. K. \& Soh, C. (2007). "An Assessment of Package-Organisation Misalignment: Institutional and Ontological Structures," European Journal of Information Systems, 16(5), 568-583.

53.Soh, C. \& Sia, S. K. (2004). “An Institutional Perspective on Sources of ERP Package-Organisation Misalignments," The Journal of Strategic Information Systems, 13(4), 375-397.

54.Soja, P. \& Paliwoda-Pekosz, G. (2009). "What Are Real Problems in Enterprise System Adoption?," Industrial Management \& Data Systems, 109(5), 610-627.

55.Strong, D. M. \& Volkoff, O. (2010). "Understanding Organization-Enterprise System Fit: A Path to Theorizing the Information Technology Artifact," MIS Quarterly, 34(4), 731-756.

56.Thomas, G. \& Jajodia, S. (2004). 'Commercial-off-the-shelf Enterprise Resource Planning Software
Implementations in the Public Sector: Practical Approaches for Improving Project Success,' Journal of Government Financial Management, 53(2), 12-19.

57.Twati, J. M. (2014). "The Influence of Societal Culture on the Adoption of Information Systems: The Case of Libya," Communications of the IIMA, 8(1), 1.

58.Volkoff, O. (1999). 'Using the Structuration Model of Technology to Analyse an ERP Implementation,' AMCIS $1999 \quad$ Proceedings, 84

59.World Bank Group. (2012). "World development indicators 2012," World Bank Publications.

60.Yen, H. R. \& Sheu, C. (2004). "Aligning ERP Implementation with Competitive Priorities of Manufacturing Firms: An Exploratory Study," International Journal of Production Economics, 92(3), 207-220.

61.Žabjek, D., Kovacic, A. \& Štemberger, M. I. (2009). "The Influence of Business Process Management and Some Other Csfs on Successful ERP Implementation," Business Process Management Journal, 15(4), 588608. 